\title{
Enfoque diagnóstico y terapéutico de la eosinofilia. A propósito de un caso
} Publicado en Internet:
14-abril-2014
Amalia Uribe Posada:
amaliauribe@hotmail.com

\author{
A. Uribe Posada ${ }^{a}, M$. Sánchez Calderón ${ }^{b}$

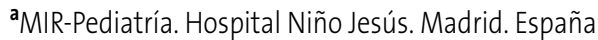 \\ - Pediatra. CS de Mejorada-Velilla de San Antonio. Madrid. España.
}

Palabras clave:

- Eosinofilia

- Parásitos

- Helmintos
La eosinofilia es el aumento del número total de eosinófilos por encima de 500/ $\mu$ l. En la edad pediátrica la causa más frecuente es la parasitosis por helmintos; otras causas frecuentes son la ingesta de algunos fármacos y las enfermedades alérgicas.

Presentamos el caso de una niña de cinco años con dolor abdominal y analítica con eosinofilia moderada en repetidas ocasiones, sin causa secundaria aparente y con normalidad en el resto de las pruebas complementarias realizadas en el centro de salud y en el hospital de referencia.

Ante una eosinofilia persistente sin causa secundaria que la explique y con normalidad de las pruebas complementarias indicadas, se recomienda tratamiento empírico con antiparasitarios.

\section{Diagnosis and treatment of eosinophilia. A case report}

Eosinophilia is the increased number of eosinophils above $500 / \mu \mathrm{l}$. The most common cause in pediatric patients is parasitic worm disease; other common causes are ingestion of some drugs and allergic diseases.

We present the case of a five year old girl with abdominal pain and moderate eosinophilia in repeated ocasions, without apparent secondary cause, and with normality in other complementary tests in the

Key words: health center and in the reference hospital.

- Eosinophilia

- Parasites

- Helminths

In case of persistent eosinophilia without secondary causes and normal complementary tests, empiric antiparasitic therapy is recommended.

\section{INTRODUCCIÓN}

La eosinofilia, aumento del número de eosinófilos totales (valor normal 350-700/ $\mu$ l), es un hallazgo frecuente en Pediatría.

La mayoría de los autores coinciden en considerarla por encima de 500 eosinófilos/ $\mu$ l. Se denomina eosinofilia leve cuando los valores están entre 500 y 1500 eosinófilos totales (por $\mu \mathrm{l}$ ), moderada entre 1500 y 5000, y grave por encima de $5000^{1,2}$. Según el mecanismo fisiopatológico, podemos clasificarla en eosinofilia primaria, secundaria e idiopática. La primaria se debe a una expansión clonal de eosinófilos, como ocurre en las neoplasias hematoló- 
gicas; la forma secundaria, la más frecuente, es la elevación de eosinófilos por trastornos alérgicos, parásitos o fármacos. La eosinofilia idiopática es aquella en la que no se logra encontrar una causa primaria o secundaria tras una evaluación exhaustiva $^{1}$.

El objetivo de este texto es presentar un caso de eosinofilia moderada y su manejo diagnóstico y terapéutico, del que hemos encontrado pocas referencias bibliográficas, ya que la mayor parte de ellas hace referencia a los trastornos eosinofílicos gastrointestinales.

\section{CASO CLÍNICO}

Niña de cinco años que consulta por cuadro de astenia, anorexia y dolor abdominal de dos semanas de evolución, sin fiebre, disuria ni vómitos o diarrea. Antecedentes personales sin relevancia, salvo que sufrió una neumonía a los 18 meses, tratada de forma ambulatoria. No hay antecedentes de atopia. Nacionalidad española. Entre sus antecedentes familiares destaca que su madre presenta urticaria crónica y sensibilización a Anisakis. Tiene un hermano de tres años asintomático.

En la exploración presenta un buen estado general, con discreta palidez facial; sin lesiones cutáneas; bien hidratada y perfundida; con peso en el percentil $75\left(P_{75}\right)$ sin pérdida de peso aparente; auscultación cardiopulmonar normal y abdomen normales; sin adenomegalias palpables; exploración neurológica normal.

Se solicitan un hemograma (Tabla 1) y una bioquímica básica, que fueron normales. También se rea- liza una analítica de heces con coprocultivo y parásitos negativos (tres muestras), y una analítica de orina con sedimento urinario normal.

Dada la cifra alta de eosinófilos se reinterroga a la familia. No refieren prurito, eccemas, estornudos ni clínica respiratoria. Tampoco bruxismo nocturno, deposiciones de características normales y no presenta en ese momento dolor abdominal. Además, no refieren viajes recientes, no tienen mascotas en el hogar y no hay ingesta actual ni reciente de fármacos.

Se repite la analítica sanguínea tres semanas después, pero la eosinofilia persiste, con unos valores de 1950 eosinófilos totales (por $\mu l$ ) y resto de hemograma normal (Tabla 1). Se amplía la bioquímica: ácido úrico 6,3 g/dl, lactato deshidrogenasa (LDH) 190 U/I, creatinfosfocinasa (CPK) 87 U/I, IgE elevada (1576 kU/I), serología para el virus de la inmunodeficiencia humana (VIH) negativa. Radiografía de tórax normal.

Tras confirmar con la segunda analítica la eosinofilia y haber realizado pruebas de primer nivel que no demostraran causa aparente, se deriva para estudio a la consulta de Hematología del hospital de referencia. Se objetiva una cifra de 2310 eosinófilos/ $\mu$ l. El resto del hemograma y la bioquímica, incluidos los niveles de ácido fólico y vitamina $B_{12}$, es normal. Las serologías, incluida la del $\mathrm{VIH}$, son negativas. Se repiten tres muestras de heces para estudio de parásitos, que también resultan negativas. Se decide instaurar terapia empírica con mebendazol, tras lo cual se objetiva una disminución de los niveles de eosinófilos hasta $370 / \mu$ l.

\begin{tabular}{|l|c|c|c|c|}
\hline \multicolumn{1}{|c|}{ Tabla 1. Hemogramas seriados en la paciente presentada } \\
\hline \multicolumn{1}{|c|}{ Hemograma } & Día 1 & Día 20 & Día 35 & Día 90 \\
\hline Leucocitos $(/ \mu \mathrm{l})$ & 8380 & 11520 & 11330 & 6190 \\
\hline Neutrófilos $(/ \mu \mathrm{l})$ & 3910 & 6320 & 5490 & 3280 \\
\hline Linfocitos $(/ \mu \mathrm{l})$ & 2290 & 2520 & 2610 & 1950 \\
\hline Monocitos $(/ \mu \mathrm{l})$ & 410 & 400 & 850 & 360 \\
\hline Eosinófilos $(/ \mu \mathrm{l})$ & 1536 & 1950 & 2310 & 370 \\
\hline Basófilos $(/ \mu \mathrm{l})$ & 50 & 60 & 80 & 50 \\
\hline Hemoglobina $(\mathrm{g} / \mathrm{dl})$ & 13,5 & 13,7 & 13,7 & 13,9 \\
\hline Plaquetas $(/ \mu \mathrm{l})$ & 363000 & 391000 & 371000 & 363000 \\
\hline
\end{tabular}




\section{DISCUSIÓN}

Presentamos un caso de eosinofilia moderada, con unas cifras de eosinófilos iniciales de 1536/ $\mu$ l y máximas de $2310 / \mu \mathrm{l}$. La eosinofilia se define como el aumento de eosinófilos totales y no como el aumento del porcentaje ${ }^{3}$. La podemos clasificar en eosinofilia primaria, secundaria e idiopática.

La eosinofilia primaria es la expansión de un clon de eosinófilos y aparece generalmente en el contexto de neoplasias hematológicas como las leucemias agudas o los trastornos mieloides crónicos. El síndrome hipereosinofílico es el aumento de eosinófilos por encima de $1500 / \mu$ l, durante un periodo mínimo de seis meses, con lesión tisular de un órgano diana (pulmón, corazón, piel y tejido nervioso) en ausencia de una causa secundaria ${ }^{1}$.

La principal causa de eosinofilia es la secundaria a parásitos. Otras causas secundarias frecuentes son la atopia, los trastornos eosinofílicos gastrointestinales y el uso de ciertos fármacos. Medicamentos de uso habitual en Pediatría como las penicilinas, las cefalosporinas, los macrólidos, las quinolonas, los antiinflamatorios no esteroideos, la ranitidina y el omeprazol son causa de eosinofilia no mediada por IgE. Nuestra paciente no estaba tomando ni había recibido recientemente ninguno de estos medicamentos.

Preguntamos por sintomatología cutánea y respiratoria, dado que el asma alérgica, la dermatitis atópica y la rinitis alérgica pueden producir eosinofilia, aunque en general asocia valores más bajos de eosinófilos (menores a 1500/ $\mu$ l) 4 $^{4}$ Dentro de los trastornos alérgicos, es importante descartar los trastornos eosinofílicos gastrointestinales como la esofagitis, la gastritis y la colitis eosinofíli$\mathrm{cas}^{5}$. Nuestra paciente solo refería un dolor abdominal inespecífico que había mejorado espontáneamente, sin ninguna otra clínica gastrointestinal. Las infecciones, principalmente las parasitarias, son la principal causa de eosinofilia en la edad pediátrica. Los helmintos, mediante la activación de los linfocitos TH2 (Thelper tipo 2), generan IgE que produce eosinofilia ${ }^{6}$. Los niveles de eosinófilos en sangre varían según la respuesta inmunitaria del huésped, el tipo de parásito y la fase en la que se encuentre. Los que más asocian eosinofilia son Ascaris lumbricoides, Strongyloides stercoralis, Hymenolepis nana, Trichura sp. y las uncinarias ${ }^{7}$. Otras menos frecuentes son Trichinella sp., Echinococcus granulosus y Toxocara canis. Los oxiuros, que son frecuentes en los niños, pueden asociar una mínima eosinofilia, habiendo autores que incluso no los consideran como causa de esta ${ }^{6,7}$. Los protozoos como Giardia lamblia y Entamoeba histolytica no producen eosinofilia ${ }^{1}$. Es importante conocer si el paciente ha realizado viajes recientes o procede de una zona endémica, para orientar hacia un tipo de parásito u otro.

Se solicitó estudio de parásitos en heces en seis ocasiones, que fue persistentemente negativo. La sensibilidad de una única muestra es baja, en torno al 40-60\%, porque depende de cómo se recoja y almacene, del número de elementos parasitarios en las heces (a menor número, menor capacidad de detección), del tipo de parásito y de la fase evolutiva en la que se encuentre; por ello se recomienda recoger tres muestras diferentes con una separación entre ellas de 2-3 días, y su análisis con técnicas de concentración parasitaria ${ }^{7}$.

La gran mayoría de las infecciones víricas y bacterianas agudas producen eosinopenia, que podría normalizar las cifras de eosinófilos en pacientes con eosinofilia previa. Una excepción serían ciertos retrovirus como el VIH o el virus de la leucemia/ linfoma de células T humanas I y II, que producen eosinofilia ${ }^{8,9}$

Tras descartar la ingesta reciente de fármacos y las causas secundarias más frecuentes, se recomienda ampliar el estudio desde Atención Primaria con bioquímica completa que incluya función renal y hepática, CPK, ácido úrico, LDH, ácido fólico y vitamina $B_{12}$ (la anemia perniciosa también se asocia a eosinofilia), radiografía de tórax (neumonía eosinofílica y síndrome de Loeffler) y citoquímico de orina (Fig. 1) ) $^{3,10}$.

Dado que los parásitos son la principal causa de eosinofilia secundaria, ante una eosinofilia confirmada y en ausencia de un diagnóstico concre- 
Figura 1. Esquema de actuación propuesto ante eosinofilia (>500/ $\mu$ l)

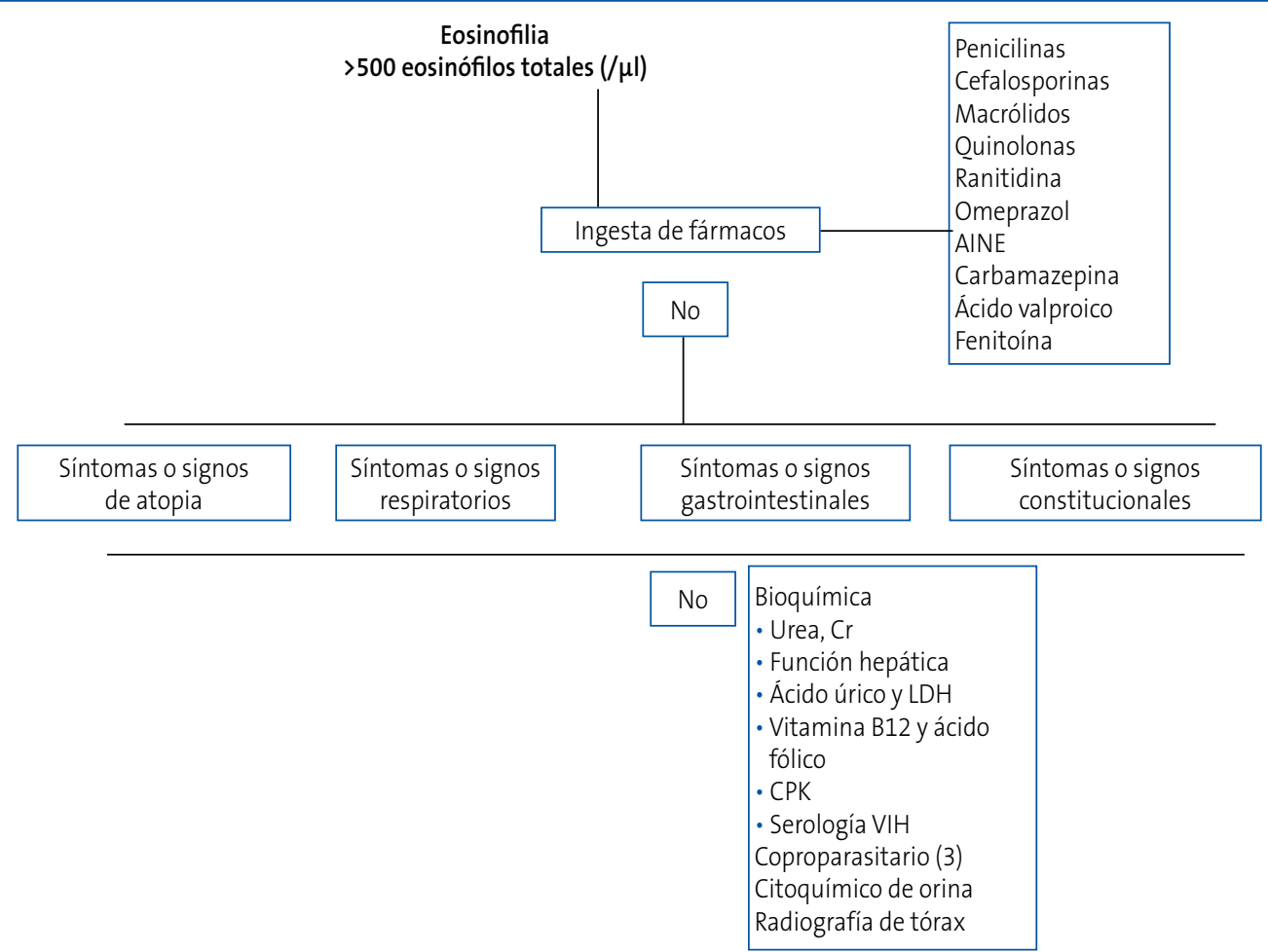

AINE: antiinflamatorios no esteroideos; CPK: creatinfosfocinasa; Cr: creatinina; LDH: lactato deshidrogenasa;

VIH: virus de la inmunodeficiencia humana.

to, estaría indicado un tratamiento empírico con antihelmínticos, dados sus pocos efectos secundarios y la baja sensibilidad diagnóstica del coproparasitario ${ }^{3}$. Esta actitud hubiese evitado, en nuestro caso, su derivación al siguiente nivel asistencial.

\section{CONFLICTO DE INTERESES}

Los autores declaran no presentar conflictos de intereses en relación con la preparación y publicación de este artículo.

\section{ABREVIATURAS}

CPK: creatinfosfocinasa - LDH: lactato deshidrogenasa

- VIH: virus de la inmunodeficiencia humana.

3. Pérez JL, Pardo J, Hernández M, Carranza C, Ángel A, Muro A. Manejo práctico de una eosinofilia. An Med Intern. 2004;21:244-52.

4. Roufosse F, Weller PF. Practical approach to the patient with hypereosinophilia. J Allergy Clin Immunol. 2010;126:39.

5. Martínez E, Molina MA, Molina M. Patología eosinofilica en la infancia. An Pediatr Contin. 2013;11:30-7. 
6. Noemi I. Eosinofilia y parasitosis. Rev Chil Pediatr. 1999;70:435-40.

7. Aparicio Rodrigo M, Díaz Cirujano A. Parasitosis intestinales (v.1/2013). Guía-ABE. Infecciones en Pediatría. Guía rápida para la selección del tratamiento antimicrobiano empírico. Disponible en www.guiaabe.es [consultado el 10/07/2013].

8. Bass DA, Gonwa TA, Szejda P, Cousart MS, DeChatelet LR, McCall CE. Eosinopenia of acute infec- tion: Production of eosinopenia by chemotactic factors of acute inflammation. J Clin Invest. 1980; 65:1265.

9. Weller P. Approach to the patient with eosinophilia [en línea]. Disponible en www.uptodate.com [consultado el 10/07/2013].

10. Pérez JL, Muro A. Conducta diagnóstica y terapéutica ante una eosinofilia importada. JANO. 2006;67: 35-9. 